\title{
Factor analysis of a move to a Karino-machi
}

\author{
H. Mori \& M. Taniguchi \\ Graduate School of Systems and Information Engineering, \\ University of Tsukuba, Japan
}

\begin{abstract}
The Great East Japan Earthquake and tsunami that struck Japan on March 11, 2011 produced widespread and severe damage, especially in the Tohoku area of northern Japan. The Fukushima nuclear power plant accident has required the long-term evacuation of many residents. For them, a Karino-machi plan has been suggested as a plan by which a town existing before the earthquake is relocated to some other locale. Nevertheless, the opinions of affected residents have not been clarified. This study clarified the expectations and factors related to moving to a Karino-machi, specifically examining all targeted persons of the Karinomachi, who now live in Iwaki, Fukushima prefecture, which is located $300 \mathrm{~km}$ north of Tokyo. Results show that the distance from each town to the Fukushima Daiichi nuclear power plant affected differences of opinions relating to the Karino-machi. Therefore, each town before the earthquake is expected to carry on the plan of Karino-machi in different ways according to that town's circumstances. Results show that personal attributes produce different opinions relating to their expectations of moving to a Karino-machi. Especially, attachment to areas where they had lived before the earthquake was a positive factor for moving to a Karino-machi, but attachment to the present living area was found to be a negative factor for moving to a Karino-machi.

Keywords: Great East Japan Earthquake, Karino-machi, move, factor analysis.
\end{abstract}

\section{Introduction}

Earthquake tremors not only collapse buildings. They can cause tsunami and landslides like those shown in Figures 1 and 2, all of which occurred with the Great East Japan Earthquake that struck on March 11, 2011. Many people were displaced in its aftermath. More than 300,000 people remained displaced from their homes in December, 2012 [1]. 
In particular, many people have been shown to need long-term refuge and life-support in emergency temporary housing, like those shown in Figures 3 and 4, because of the influence of the radioactivity by Fukushima Daiichi nuclear power plant accident. These circumstances dictate that many will not return to their former homes even if they want to do so. For them, the Karino-machi plan is suggested. It is pushing forward now.

The Karino-machi [2] is the first of its kind in Japan. The Karino-machi plan is moving town government functions to another city (or town). They then govern themselves in that city. This arrangement is intended to enable them to reconstruct and revive their home areas smoothly. People who are targeted for Karino-machi participation should devote attention to them because they must decide whether they will live in the Karino-machi in the future or not. However, because of a lack of information related to Karino-machi, it is difficult to administer them. These circumstances complicate reconstruction and revival efforts.

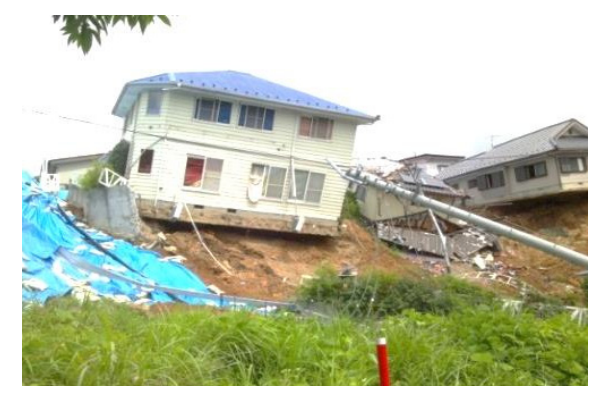

Figure 1: Damage of landslide.

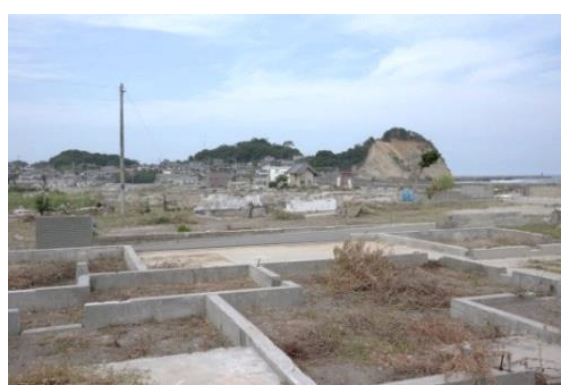

Figure 2: Damage of tsunami.

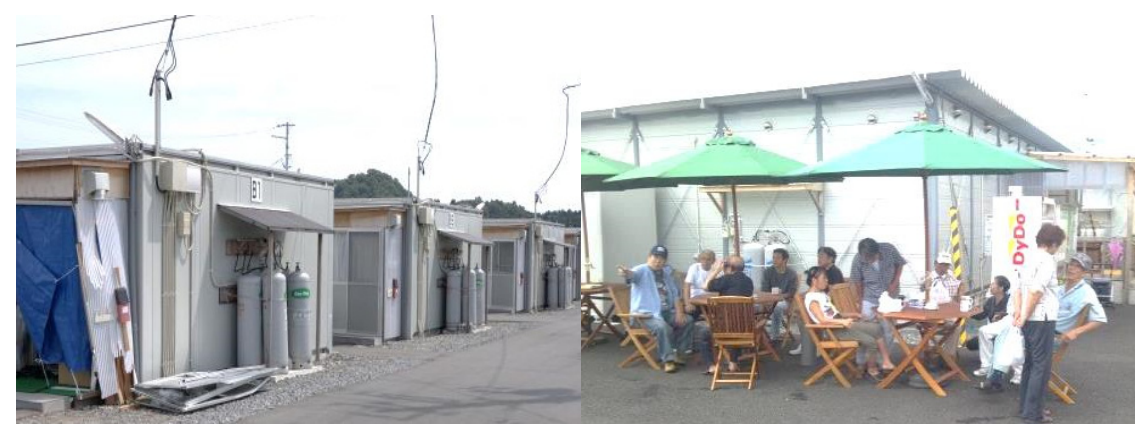

Figure 3: Emergency temporary housing.
Figure 4: People in emergency temporary housing.

Japanese newspapers [3] have investigated how targeted people think about the Karino-machi. They also examined recent tendencies of Karino-machi. A 
panel study targeted people in Karino-machi. Nevertheless, no report in the literature describes a study that has applied factor analysis to assess approval or disapproval.

For smooth reconstruction and revival, people who must change their living place because of this earthquake must decide where to live. Moreover, it is useful to leave a record of the action for this earthquake disaster for the future when a similar problem occurs. Therefore this study assesses this aspect of the East Japan great earthquake disaster and conducts a questionnaire survey about the consciousness of the people who are targeted for participation in Karino-machi, which is the first conducted in the country. The questionnaire surveys clarify what factors reveal a tendency of hoping to move to a Karino-machi. Finally, we will try to show useful information for future government assessment of the Karino-machi.

\section{Contents and benefits of this study}

Based on the purpose explained above, we researched Iwaki city, Fukushima prefecture. Iwaki city accepted more than 20,000 displaced people (June, 2012). Iwaki city also accepted many people who were targeted as Karino-machi residents. In addition, the Japanese government chose to build 1,800 public housing units for displaced people in Iwaki city [4]. Actually, the Japanese government planned to produce 3,700 public housing units for refugees overall. The plan of producing public housing in Iwaki city has advanced to the present: March, 2014. Based upon the foregoing, Iwaki city is the only area for which it is possible to discuss the Karino-machi phenomenon.

Iwaki city, with population of 325,000 , is located $300 \mathrm{~km}$ north of Tokyo. In addition, Iwaki city occupies $1.31 \mathrm{~km}^{2}$, making it an extremely large city area in Japan. Figure 5 shows the location of Iwaki city. Figure 6 shows the locations of towns neighboring Iwaki city. People who lived in these towns before the earthquake are the main targets of Karino-machi.

The study contents are the following.

1) First, the investigation is explained in section 3.

2) Section 4 clarifies people's consciousness about Karino-machi.

3) Section 5 presents a factor analysis about the move to the Karino-machi, particularly addressing attachment to the area where people had lived before the earthquake.

Based on the contents explained above, this study has several benefits.

1) We sent questionnaires to all the people targeted as present or potential Karino-machi residents in Iwaki city. The wealth of responses answers supports the use of factor analysis.

2) We specifically examine Karino-machi: the first such study in Japan.

3) Results are useful for advancing to reconstruction and revival from this earthquake. 


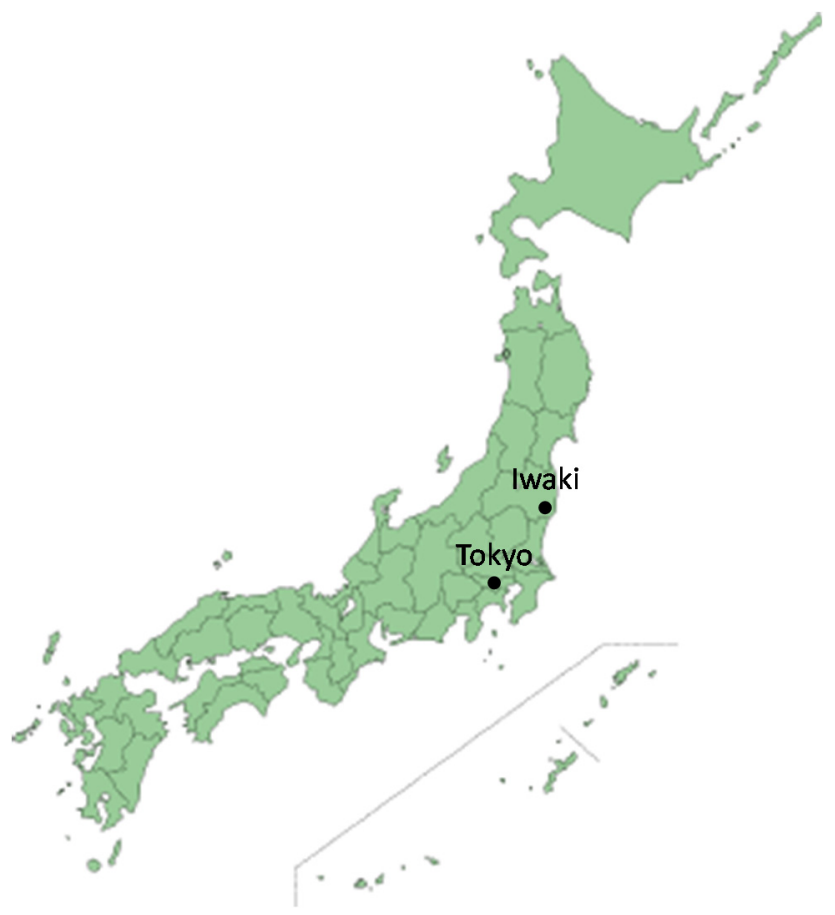

Figure 5: Iwaki city location.

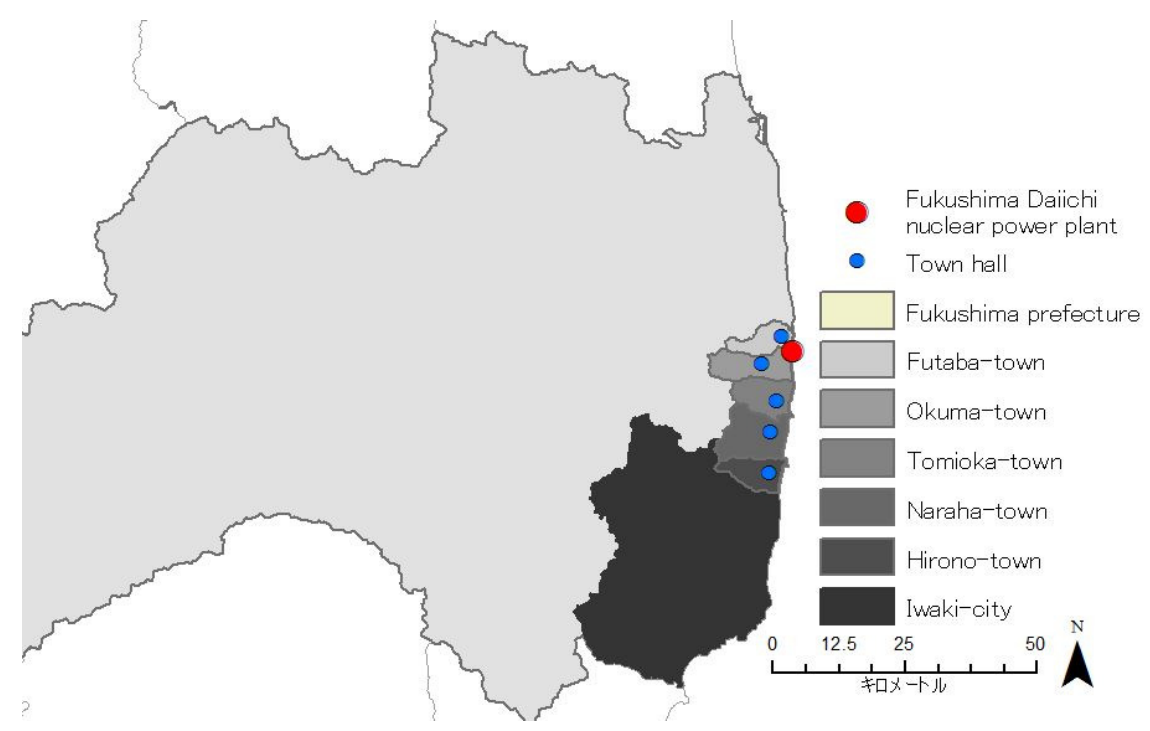

Figure 6: Towns neighboring Iwaki city. 


\section{Investigation summary}

We conducted a questionnaire survey of all emergency temporary housing residents in Iwaki city during October-November, 2012. In the survey, the consciousness for the Karino-machi and hopes of moving to the Karino-machi are elicited. Furthermore, many people faced living in a different place before this earthquake. For that reason, attachment (For this study, "attachment" is defined as "preference for a place the person lives in or lived in".) to areas where they had lived before the earthquake and attachment to present living areas are queried.

Iwaki city has 32 emergency temporary housing units, 31 of which are for people relocated from outside of Iwaki city. We sent 2,980 survey forms and finally obtained 672 responses.

\section{Consciousness about Karino-machi}

This survey asked about recognition, the way of thinking, and hopes of moving to the Karino-machi. Figure 7 and Figure 8 depict the results.

1) In Figure 7, more than $50 \%$ of the people in this survey do not understand the plan of the Karino-machi. Results also clarified that persons who are targeted for the Karino-machi were unable to recognize the Karino-machi sufficiently.

2) In Figure 7, about 50\% people in the survey answered that they do not know about wanting to plan a Karino-machi. They also think that it is impossible to produce a Karino-machi. However, the number of people who have a positive opinion about Karino-machi and a negative opinion about the Karino-machi are about same.

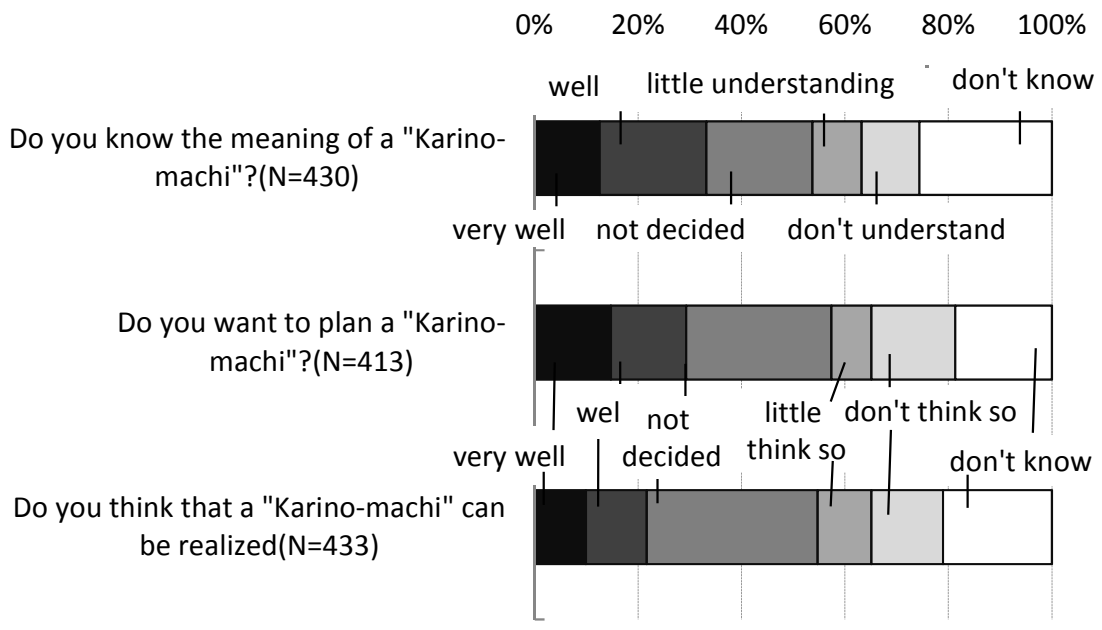

Figure 7: Consciousness related to a Karino-machi. 


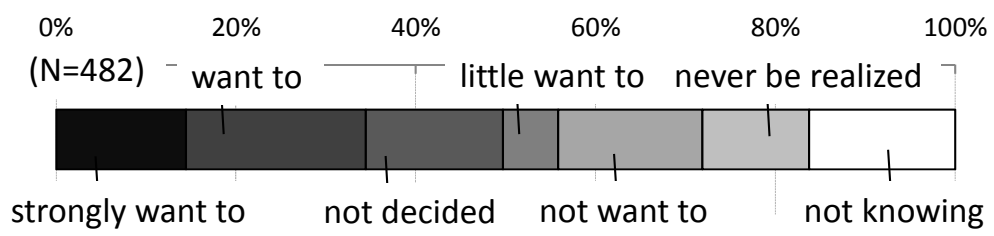

Figure 8: Hope of moving to a Karino-machi.

3) Figure 8 shows that the number of people who want to live in the Karino$m a c h i$, if it can be realized, is larger than the number of others. Many people tend to move to Karino-machi when they are realized.

\section{Factor analysis of a move to a Karino-machi}

In this section, we will clarify what factors affect the move to the Karino-machi using Covariance Structure Analysis. Figure 9 presents analysis results and the following considerations.

1) In Figure 9, people with an attachment to areas where they had lived before the earthquake show a tendency of wanting to live in a Karino-machi. Particularly, the tendency was as strong in people with strong pride in local culture and tradition.

2) However, people with attachment to the present living area, show a tendency by which they do not want to live in a Karino-machi.

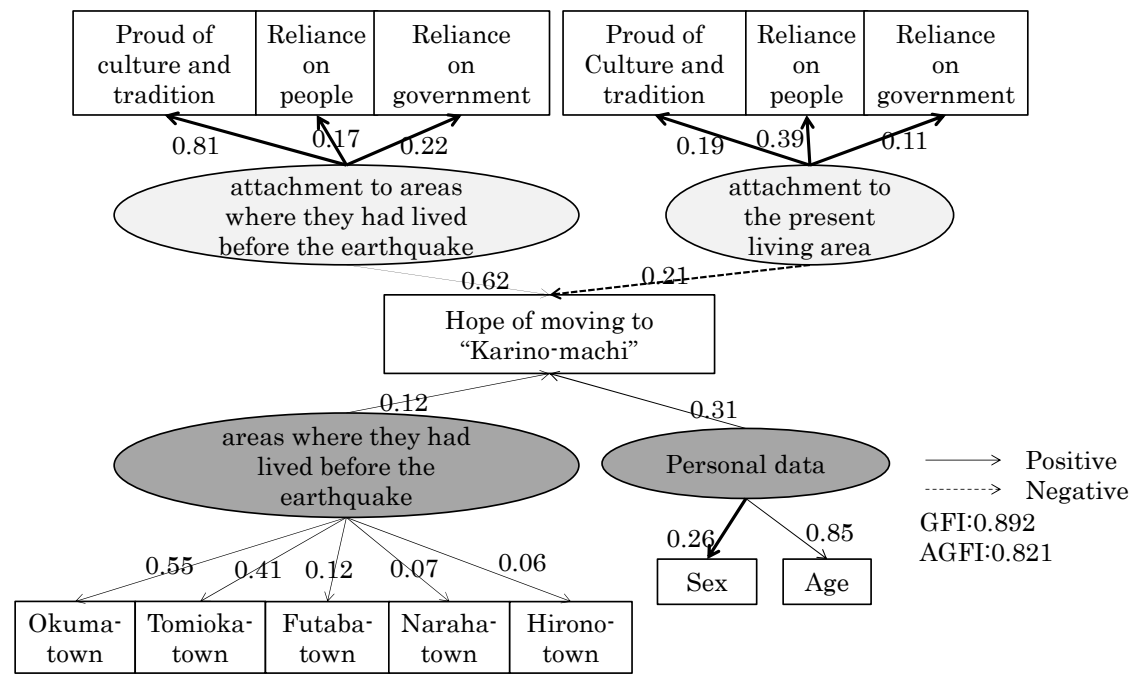

Figure 9: Results of factor analysis related to Karino-machi. 
3) In this analysis, the factor of age strongly influenced moving to the Karinomachi. The hope of moving to the Karino-machi was clarified as strongest among young and old people.

4) Considering Figures 6 and 9, the distance from Fukushima Daiichi nuclear power plant to each area where they had lived before the earthquake is related to hope for moving to the Karino-machi. The people who lived in towns close to Fukushima Daiichi nuclear power plant show a strong tendency of hoping to live in the Karino-machi.

\section{Conclusions}

Results that this study provided are the following.

1) At the point of this survey, Karino-machi was advanced as a plan. However, many targeted people replied expressed "not understanding" or "not knowing" about the Karino-machi information.

2) Attachment to areas where they had lived before the earthquake is a positive factor for moving to a Karino-machi, but attachment to the present living area, Iwaki city, was found to be a negative factor for moving to a Karino-machi. In other words, attachment to the area of origin is an important factor for moving to a Karino-machi.

3) Results show that popular awareness such as "attachment" and the distance from Fukushima Daiichi nuclear power plant are important factors for moving to the Karino-machi. Additionally, it might be expected that Okuma town, Tomioka town, and Naraha town can undergo smooth reconstruction and revival by pushing forward a Karino-machi because they move their government office functions outside of town now. However, the Naraha town and Hirono town governments are planning to get back to their own towns. Therefore, it is faster for Naraha town and Hirono town to reconstruct and revive their town directly. We must consider special circumstances when pushing forward the wider use of Karino-machi measures.

\section{References}

[1] Reconstruction Agency, Japan, statement in 12 December 2012. http://www.reconstruction.go.jp/topics/20121212 hinansyasuutyousa.pdf

[2] Reconstruction Agency, Japan, Grand design for the Great East Japan Earthquake. http://www.reconstruction.go.jp/topics/20120904_gdhonbun. pdf

[3] Asahi newspaper, Japan, 24 September 2012.

[4] Reconstruction Agency, Japan, The first plan for public housing in Fukushima prefecture. http://wwwcms.pref.fukushima.jp/download/1/seibi2. pdf 